\title{
METODE KLASIFIKASI JARINGAN SYARAF TIRUAN BACKPROPAGATION PADA MAHASISWA STATISTIKA UNIVERSITAS TERBUKA
}

\section{Backpropagation Artificial Neural Network Classification Method In Statistics Students of Open University}

\author{
Siti Hadijah Hasanah ${ }^{1 *}$, Sri Maulidia Permatasari ${ }^{2}$ \\ ${ }^{1,2}$ Program Studi Statistika, Fakultas Sains dan Teknologi, Universitas Terbuka \\ Jl. Pd. Cabe Raya, Pd Cabe Udik Pamulang, Tangerang Selatan, 15418, Indonesia \\ e-mail: ${ }^{1^{*}}$ sitihadijah@ecampus.ut.ac.id; ${ }^{2}$ srimaulidia@ecampus.ut.ac.id \\ Corresponding Author
}

\begin{abstract}
Abstrak
Jaringan Syaraf Tiruan (JST) Backpropagation merupakan salah satu JST yang menggunakan algoritma pembelajaran terawasi. Tujuan penelitian ini yaitu untuk mengetahui parameter dan mengukur akurasi ketepatan klasifikasi terhadap status mahasiswa Prodi Statistika Univeritas Terbuka. Berdasarkan hasil, simulasi didapatkan 15 parameter yang dapat mempengaruhi status mahasiswa, di antaranya yaitu jenis kelamin, usia, pendidikan (SLTA/SMK, Diploma, S1, dan S2), status pernikahan, status pekerjaan (tidak bekerja, karyawan swasta, wiraswasta, dan PNS), tahun registrasi awal, jumlah registrasi, SKS tempuh, dan IPK. Sedangkan untuk akurasi ketepatan klasifikasi digunakan fungsi aktivasi dan learning rate yang dapat menghasilkan nilai kuadrat tengah galat (KTG) yang minimum pada data training. Hasil simulasi tersebut diterapkan pula pada data testing dengan nilai cut off point sebesar 0,3481, maka didapatkan ketepatan akurasi dengan kurva ROC pada data training untuk mahasiswa tidak aktif 99,43\% dan aktif $99,14 \%$, sedangkan pada data testing mahasiswa tidak aktif $94,00 \%$ dan aktif $93,94 \%$. Jadi dari penelitian ini dapat disimpulkan JST Backpropagation merupakan salah satu metode yang sangat baik dalam penerapan metode klasifikasi.
\end{abstract}

Kata Kunci : Backpropagation, cut off point, fungsi aktivasi, jaringan syaraf tiruan, learning rate

\begin{abstract}
Backpropagation Artificial Neural Network (ANN) is an ANN that uses a supervised learning algorithm. The purpose of this study is to determine the parameters and measure the accuracy of the classification accuracy of the student status of the Open University Statistics Study Program. Based on the results, the simulation obtained 15 parameters that can affect student status, including gender, age, education (Senior High School, Diploma, Bachelor, and Magister), marital status, employment status (not working, private employees, entrepreneurs, and civil servants), initial registration year, registration number, semester credit system, and GPA). Meanwhile, for the classification accuracy, the activation function and the learning rate are used minimum mean square of error (MST) on training data. The simulation results are also applied to the testing data with a cut-off point value of 0.3481, so the accuracy of the ROC curve is obtained in the training data for not active students is $99.43 \%$ and $99.14 \%$ active, while the testing data for not active students is $94.00 \%$. and active $93.94 \%$. So from this research, it can be concluded that ANN Backpropagation is a very good method in applying the classification method.
\end{abstract}

Keywords : Backpropagation, cut-off point, activation function, artificial neural network, learning rate 


\section{PENDAHULUAN}

Universitas Terbuka (UT) memiliki beberapa fakultas salah satunya Fakultas Matematika dan Ilmu Pengetahuan Alam (FMIPA), FMIPA didirikan pada tahun 1984 dan kini telah berganti nama menjadi Fakultas Sains dan Teknologi (FST). UT menawarkan program studi S1 Statistika dan telah berhasil meluluskan mahasiswa Program Studi Statistika dari berbagai macam karakteristik yang dimiliki mahasiswa UT [1].

Universitas Terbuka (UT) memiliki 39 kantor layanan yang tersebar di seluruh Indonesia dan salah satu universitas yang pertama kali menerapkan sistem pembelajaran jarak jauh dan terbuka. Jarak jauh yaitu pembelajaran tidak dilakukan secara tatap muka, melainkan melalui media cetak seperti modul dan non cetak seperti audio/video, komputer, internet [2]. Sedangkan Terbuka yaitu UT tidak ada pembatasan jangka waktu penyelesaian studi, tidak ada penerapan sistem drop out (DO), tidak ada pembatasan tahun kelulusan ijazah, umur, dan waktu pendaftaran [3]. Maka hal ini yang membuat UT memiliki kelebihan dari Universitas lainnya di Indonesia.

Berdasarkaan kelebihan berkuliah di UT ada permasalahan yang harus dihadapi universitas salah satunya adalah status mahasiswa. Hal ini dikarenakan mahasiswa diberikan kemudahan untuk meregristrasikan dirinya kapan saja sehingga banyak mahasiswa yang berstatus tidak aktif pada suatu semester dan tidak ketahui pasti kapan mahasiswa tersebut menjadi mahasiswa aktif kembali. Penelitian ini dilakukan untuk mengklasifikasikan status mahasiswa aktif dan tidak aktif pada Prodi Statistika dengan menggunakan metode Artificial Intelligent ( $A I$ ) yang salah satunya yaitu metode Jaringan Syaraf Tiruan (JST) dengan menggunakan Algoritma Backpropagation. Backpropagation merupakan algoritma supervised learning dan multi layer dengan mengubah bobot-bobot pada masing-masing lapisan dengan langkah pertama adalah mengatur jumlah lapisan input, tersembunyi, dan output [4]. Pada tahun 1999-2000 AI kurang berkembang dikarenakan keterbatasan dalam hal komputasi dan pendanaan, hingga pada tahun 2010 AI membawa peningkatan besar, baik dari sektor negeri maupun swasta. Sehinggal model JST dapat berkembang menjadi lebih kompleks [5].

Jaringan Syaraf Tiruan (JST) merupakan suatu metode komputasi yang meniru cara kerja otak manusia yang terdiri dari neuron-neuron, dan antar neuron tersebut saling berhubungan [6]. Keuntungan menggunakan JST dari pada metode klasifikasi lain yaitu sifatnya yang non parametrik [7], sangat baik bila parameter yang digunakan cukup banyak, dan dapat bekerja dengan data yang cukup besar [8].

Tujuan penelitian ini yaitu untuk mengetahui parameter-parameter yang digunakan untuk pengklasifikasian status mahasiswa yang aktif dan tidak aktif yang nantinya akan dibuatkan suatu kebijakan atau solusi untuk mengatasi mahasiswa yang kemungkinan akan berstatus tidak aktif dan untuk mengetahui ketepatan klasifikasi status mahasiswa di Prodi Statistika UT dengan menggunakan metode Jaringan Syaraf Tiruan Backpropagation [9].

Data terbagi menjadi dua bagian yaitu data training dan data testing, pada data training dilakukan simulasi dengan memaksimalkan fungsi aktivasi dan learning rate $(\alpha)$ [10]. Hasil simulasi yang digunakan adalah model JST Backpropagation dengan nilai bobot, fungsi aktivasi, dan learning rate $(\alpha)$ yang menghasilkan nilai KTG yang minimum. Hasil simulasi dari data training diterapkan pada data testing dan di ukur akurasiannya pada kedua data tersebut dengan menggunakan kurva ROC [11].

\section{METODE PENELITIAN}

Data yang digunakan dalam penelitian ini adalah data sekunder, berupa data Karakteristik Mahasiswa Universitas Terbuka Program Studi Statistika Tahun 2009.1 s/d 2019.2. Data terbagi menjadi 2 yaitu data training 1046 mahasiswa dan data testing 447 mahasiswa yang diambil untuk penerapan metode JST Backpropagation dapat dilihat pada Tabel 1, sebagai berikut: 
Tabel 1. Karakteristik Mahasiswa Universitas Terbuka Program Studi Statistika

\begin{tabular}{|clcl|}
\hline Variabel & Keterangan & Skala Pengukuran & Kategori \\
\hline X1 & Jenis Kelamin & Nominal & $1=$ Pria \\
& & & $2=$ Wanita \\
X2 & Usia & Interval & \\
X3 & Pendidikan & Ordinal & $1=$ SLTA/SMK \\
& & & $2=$ Diploma \\
& & $3=$ S 1 \\
& & $4=$ S2 \\
X4 & Status Pernikahan & $5=$ S3 \\
& & & $1=$ Belum Menikah \\
X5 & Status Pekerjaan & Nominal & $2=$ Menikah \\
& & & $1=$ Tidak Bekerja \\
& & Nominal & $2=$ Karyawan Swasta \\
& & & $3=$ Wiraswasta \\
X6 & Tahun Registrasi Awal & & $4=$ PNS \\
X7 & Jumlah Registrasi & & $5=$ TNI/Polri \\
X8 & SKS Tempuh & Interval & \\
X9 & IPK & Interval & \\
Y & Status Mahasiswa & Interval & \\
& & Interval & \\
& & Nominal & $0=$ Tidak Aktif \\
& & & $1=$ Aktif \\
& & & \\
\hline
\end{tabular}

Di bawah ini merupakan gambar flowchart metode JST Backpropagation :

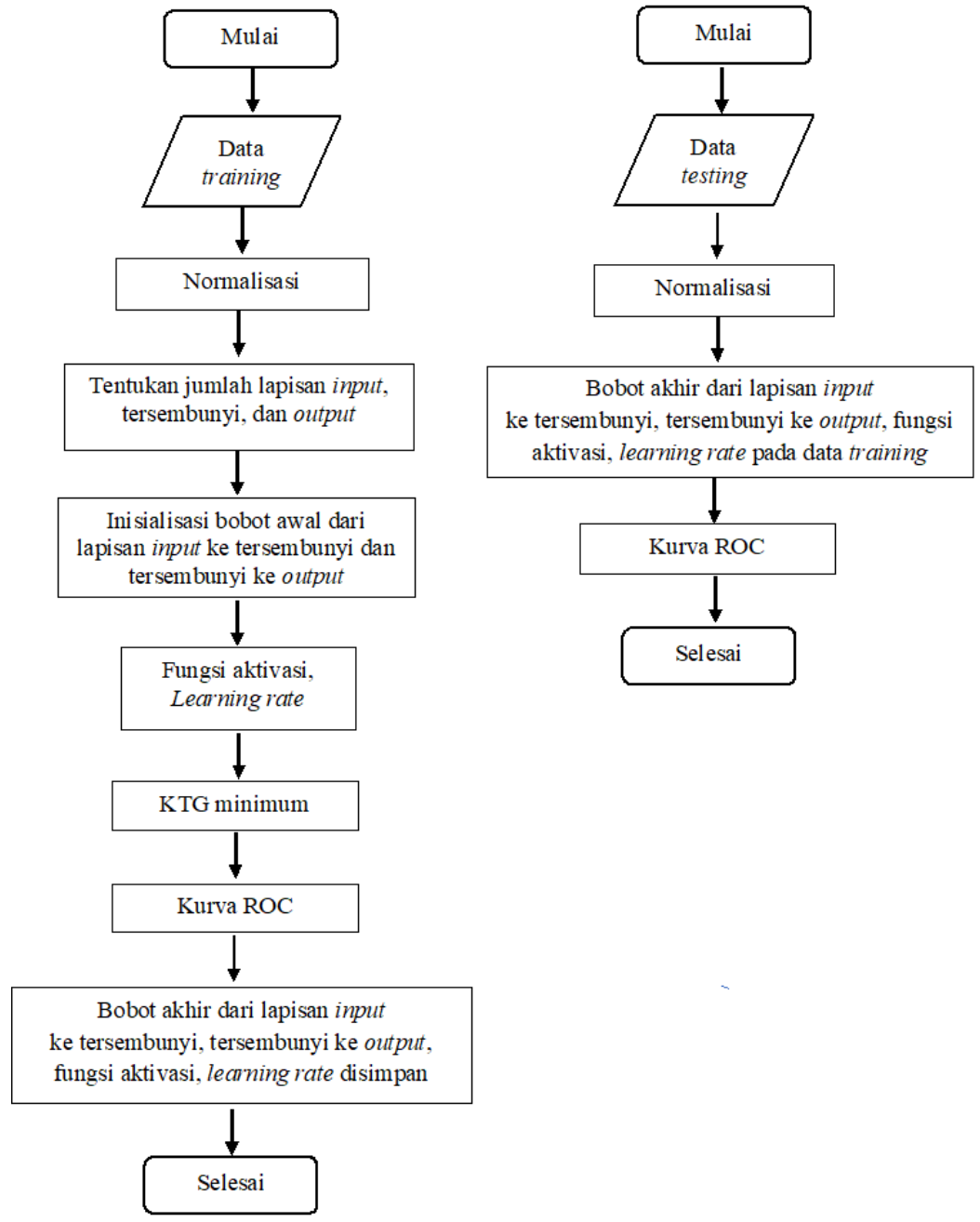

Gambar 1. Flowchart JST Backpropagation 


\section{HASIL DAN PEMBAHASAN}

Metode Jaringan Syaraf Tiruan (JST) adalah pemrosesan informasi yang terinspirasi oleh sistem syaraf Biologi. JST mampu mengenali kegiatan dengan berbasis data pada masa lalu. Data masa lalu akan dipelajari oleh JST sehingga mempunyai kemampuan untuk memberi keputusan terhadap data yang belum pernah dipelajari [9].

\subsection{Backpropagation}

Backpropagation merupakan algoritma pembelajaran terawasi yang terdiri dari lapisan input, lapisan tersembunyi, dan output dengan mengubah bobot-bobot yang terhubung pada masing-masing lapisan [12].

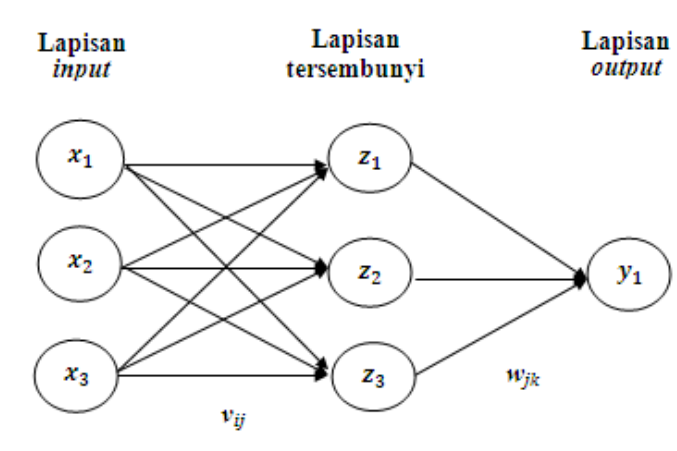

Gambar 2. Jaringan Syaraf Tiruan [13]

Gambar 2 di atas merupakan contoh arsitektur JST Backpropagation yang menunjukkan bahwa $x_{1}$, $x_{2}, x_{3}$ merupakan lapisan input, $z_{1}, z_{2}, z_{3}$ merupakan lapisan tersembunyi, sedangkan $y_{1}$ merupakan lapisan output. Antara lapisan input ke lapisan tersembunyi dihubungkan oleh masing-masing bobot sama halnya antara lapisan tersembunyi ke lapisan output dihubungkan oleh masing-masing bobot. Setiap lapisan input, bobot, dan lapisan tersembunyi didapatkan dengan melakukan simulasi, diharapkan menghasilkan nilai error dalam hal ini yaitu kuadrat tengah galat (KTG) minimum.

Model JST Backpropagation adalah sebagai berikut:

$$
y_{k}=f_{k}\left(\sum_{j=1}^{p} w_{j k} f_{j}\left(v_{0 j}+\sum_{i=1}^{n} x_{i} v_{i j}\right)+w_{0 k}\right)
$$

$w_{0 k}=$ bobot bias pada unit output $y_{k}$

$v_{0 j}=$ bobot bias pada unit tersembunyi $z_{j}$

$v_{i j}=$ bobot garis dari unit $x_{i}$ ke unit tersembunyi $z_{j}$

$w_{j k}=$ bobot garis dari $z_{j}$ ke unit output $y_{k}$

$f_{k}=$ fungsi aktivasi pada unit tersembunyi ke output

$f_{j} \quad$ = fungsi aktivasi pada unit input ke tersembunyi

$x_{i}=$ unit input ke- $i$

$z_{j} \quad=$ unit tersembunyi ke $-j$

$y_{k}=$ unit output ke- $k$

$i=1, \ldots, n$

$j \quad=1, \ldots, p$

$k=1, \ldots, l$

$n=$ banyaknya unit input

$p=$ banyaknya unit tersembunyi

$l=$ banyaknya unit output 


\subsection{Normalisasi}

Normalisasi digunakan untuk membuat hasil output pada JST Backpropagation berada pada nilai 0 sampai dengan 1 . Normalisasi dapat menghasilkan ketepatan klasifikasi yang cukup tinggi pada status mahasiswa Prodi Statistika UT [14], dengan menggunakan rumus sebagai berikut :

$$
x=\frac{0,8(x-a)}{b-a}+0,1
$$

\subsection{Fungsi Aktivasi}

Fungsi aktivasi merupakan suatu fungsi yang digunakan untuk membawa nilai input menuju output yang diinginkan. Fungsi ini harus memenuhi beberapa syarat yaitu kontinu, terdiferensial dengan mudah, dan fungsi yang tidak turun. Fungsi aktivasi yang digunakan dalam JST Backpropagation yaitu fungsi sigmoid biner, fungsi tangen sigmoid, dan fungsi linear [15].

\subsection{Hasil Eksplorasi Data}

Berikut ini merupakan hasil eksplorasi data yang menggambarkan status mahasiswa Prodi Statistika UT berdasarkan jenis kelamin, kelompok usia, pendidikan, status pernikahan, dan status pekerjaan.

Tabel 2. Status Mahasiswa Bedasarkan Jenis Kelamin

\begin{tabular}{|lcc|}
\hline \multirow{2}{*}{ Jenis Kelamin } & \multicolumn{2}{c|}{ Persentase (\%) } \\
\cline { 2 - 3 } & Tidak Aktif & Aktif \\
\hline Pria & 35,9 & 64,1 \\
Wanita & 29,1 & 70,9 \\
\hline
\end{tabular}

Berdasarkan Tabel 2 di atas menunjukkan bahwa persentase wanita yang aktif sebagai mahasiswa UT Prodi Statistika yaitu sebesar 70,9\%, persentase tersebut lebih besar bila dibandingkan dengan pria yaitu sebesar $64,1 \%$. Maka dapat disimpulkan wanita lebih mendominasi mengambil program studi Statistika dibandingkan dengan pria.

Tabel 3. Status Mahasiswa Berdasarkan Kelompok Usia

\begin{tabular}{|lcc|}
\hline \multirow{2}{*}{ Kelompok Usia } & \multicolumn{2}{c|}{ Status Mahasiswa (\%) } \\
\cline { 2 - 3 } & Tidak Aktif & Aktif \\
\hline$\leq 25$ & 8,5 & $91,5 \mathrm{z}$ \\
$26-35$ & 39,1 & 60,9 \\
$36-45$ & 48,8 & 51,2 \\
$46-55$ & 44,1 & 55,9 \\
$\geq 56$ & 40,0 & 60,0 \\
\hline
\end{tabular}

Tabel 3 di atas menunjukkan bahwa persentase yang paling besar sebagai mahasiswa aktif yaitu pada kelompok usia $\leq 25$ tahun sebesar 91,5\%, diikuti pada kelompok usia $26-35$ tahun, $\geq 56$ tahun, $46-55$ tahun, dan $36-45$ tahun. Maka dapat disimpulkan kelompok usia $\leq 25$ tahun adalah mahasiswa yang paling banyak mengambil Prodi Statistika dikarenakan pada usia tersebut merupakan mahasiswa yang fresh graduate dari sekolah menengah keatas.

Tabel 4. Status Mahasiswa Berdasarkan Pendidikan

\begin{tabular}{|lcc|}
\hline \multirow{2}{*}{ Pendidikan } & \multicolumn{2}{c|}{ Status Mahasiswa (\%) } \\
\cline { 2 - 3 } & Tidak Aktif & Aktif \\
\hline SLTA & 31,9 & 68,1 \\
Diploma & 35,9 & 64,1 \\
S1 & 29,0 & 71,0 \\
S2 & 0,0 & 100,0 \\
S3 & 100,0 & 0,0 \\
\hline
\end{tabular}


Tabel 4 di atas menunjukkan bahwa persentase pendidikan S2 dan S1 yang berstatus aktif sebagai mahasiswa UT Prodi Statistika yaitu sebesar S2 100\% dan S1 yaitu 71\%. Hal ini dapat disimpulkan bahwa status mahasiswa aktif yang telah berpendidikan S1 dan S2 lebih mudah mengikuti perkuliahan di Prodi Statistika karena telah mempelajari Statistika pada saat mengikuti perkuliahan sebelumnya dan mengambil Statistika sebagai penunjang untuk meningkatkan kompetensi dalam hal analisis dan pengolahan data. Sedangkan yang berpendidikan S3 tidak aktif $100 \%$ setelah dilakukan analisis diketahui bahwa hanya terdapat 1 mahasiswa S3 saja yang pada saat itu sedang tidak aktif menjadi mahasiswa.

Tabel 5. Status Mahasiswa Menurut Status Pernikahan

\begin{tabular}{|lcc|}
\hline \multirow{2}{*}{ Status Pernikahan } & \multicolumn{2}{c|}{ Status Mahasiswa $(\boldsymbol{\%})$} \\
\cline { 2 - 3 } & Tidak Aktif & Aktif \\
\hline Belum Menikah & 26,1 & 73,9 \\
Menikah & 38,0 & 62,0 \\
\hline
\end{tabular}

Tabel 5 di atas menunjukkan bahwa persentase mahasiswa aktif yang berdasarkan status pernikahan diketahui bahwa mahasiswa yang belum menikah pada Prodi Statistika yaitu sebesar 73,9\%. Hal ini menunjukkan bahwa mahasiswa yang belum menikah lebih mudah mengikuti proses perkuliahan di UT pada Prodi Statistika.

Tabel 6. Mahasiswa Berdasarkan Status Pekerjaan

\begin{tabular}{|lcc|}
\hline \multirow{2}{*}{ Status Pekerjaan } & \multicolumn{2}{c|}{ Status Mahasiswa $(\%)$} \\
\cline { 2 - 3 } & Tidak Aktif & Aktif \\
\hline Tidak Bekerja & 27,0 & 73,0 \\
Karyawan Swasta & 30,5 & 69,5 \\
Wiraswasta & 26,4 & 73,6 \\
PNS & 41,2 & 58,8 \\
TNI/Polri & 100,0 & 0,0 \\
\hline
\end{tabular}

Tabel 6 di atas menunjukkan bahwa mahasiswa aktif di Prodi Statistika adalah mahasiswa yang bekerja sebagai wiraswasta sebesar 73,6\% dan tidak bekerja sebesar 73,0\%. Hal ini menunjukkan bahwa mahasiswa yang bekerja sebagai wiraswasta dan yang tidak bekerja lebih mudah mengikuti proses perkuliahan di Prodi Statistika.

\subsection{Simulasi JST Backpropagation}

Selanjutnya dilakukan pengklasifikasian untuk status mahasiswa Prodi Statistika dengan menggunakan metode Jaringan Syaraf Tiruan (JST) Backpropagation. Simulasi dilakukan dengan memaksimalkan fungsi aktivasi dan learning rate $(\alpha)$, maka Model JST Backpropagation pada data training yang terbentuk pada unit lapisan input yaitu 15 unit, lapisan unit output 1 dan 8 lapisan unit tersembunyi. Hasil simulasi dapat dilihat pada tabel 7 di bawah ini.

Tabel 7. Hasil Simulasi Fungsi Aktifasi Dan Learning Rate

\begin{tabular}{|cccccccccc|}
\hline No & \multicolumn{2}{c}{$\begin{array}{c}\text { Fungsi } \\
\text { Aktivasi }\end{array}$} & $\begin{array}{c}\text { Learnig } \\
\text { rate }(\boldsymbol{\alpha})\end{array}$ & KTG & No & Fungsi Aktivasi & $\begin{array}{c}\text { Learnig } \\
\text { rate }(\boldsymbol{\alpha})\end{array}$ & KTG \\
\hline 1 & Log & Linear & 0,01 & 0,015002 & 11 & Log & Linear & 0,5 & 0,013088 \\
2 & Tan & Linear & 0,01 & 0,014702 & 12 & Tan & Linear & 0,5 & 0,013705 \\
3 & Log & Linear & 0,1 & 0,013049 & 13 & Log & Linear & 0,6 & 0,016399 \\
4 & Tan & Linear & 0,1 & 0,007924 & 14 & Tan & Linear & 0,6 & 0,010384 \\
5 & Log & Linear & 0,2 & 0,014674 & 15 & Log & Linear & 0,7 & 0,012494 \\
6 & Tan & Linear & 0,2 & 0,013854 & 16 & Tan & Linear & 0,7 & 0,010625 \\
7 & Log & Linear & 0,3 & 0,013561 & 17 & Log & Linear & 0,8 & 0,014627 \\
8 & Tan & Linear & 0,3 & 0,012849 & 18 & Tan & Linear & 0,8 & 0,005195 \\
9 & Log & Linear & 0,4 & 0,014409 & 19 & Log & Linear & 0,9 & 0,012066 \\
10 & Tan & Linear & 0,4 & 0,014921 & 20 & Tan & Linear & 0,9 & 0,013741 \\
\hline
\end{tabular}


Berdasarkan tabel di atas menunjukkan bahwa fungsi aktivasi tangen sigmoid pada lapisan input ke lapisan tersembunyi dan linear pada lapisan tersembunyi ke lapisan output serta learning rate 0,8 menghasilkan nilai KTG yang minimum yaitu sebesar 0,005195. Maka berdasarkan hasil simulasi yang telah dilakukan maka model JST Backpropagation adalah sebagai berikut :

$$
y_{k}=f_{k}\left(\sum_{j=1}^{8} w_{j k} f_{j}\left(v_{0 j}+\sum_{i=1}^{15} x_{i} v_{i j}\right)+w_{0 k}\right)
$$

Jumlah 15 unit input terdiri dari jenis kelamin, usia, pendidikan (SLTA/SMK, Diploma, S1, S2), status pernikahan, status pekerjaan (tidak bekerja, karyawan swasta, wiraswasta, PNS), tahun registrasi awal, jumlah registrasi, SKS tempuh, dan IPK.

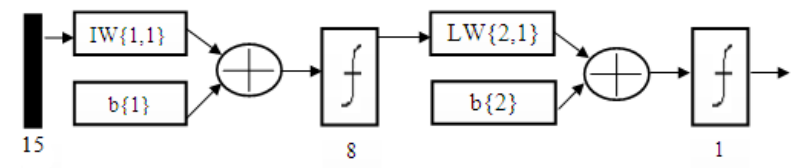

\section{Gambar 3. Hasil Simulasi Jaringan Syaraf Tiruan Backpropagation}

Gambar di atas menunjukkan bahwa simulasi yang telah didapatkan dengan 15 unit lapisan input, 8 unit lapisan tersembunyi, 1 unit lapisan output, IW $\{1,1\}$ dan $b\{1\}$ adalah bobot, bias akhir yang terdapat pada lapisan input ke lapisan tersembunyi, $\mathrm{LW}\{2,1\}$ dan $\mathrm{b}\{2\}$ adalah bobot, bias akhir yang terdapat pada lapisan tersembunyi ke lapisan output.

Hasil output pada JST Backpropagation dilakukan analisis lanjutan dengan menggunakan kurva ROC sebagai berikut :

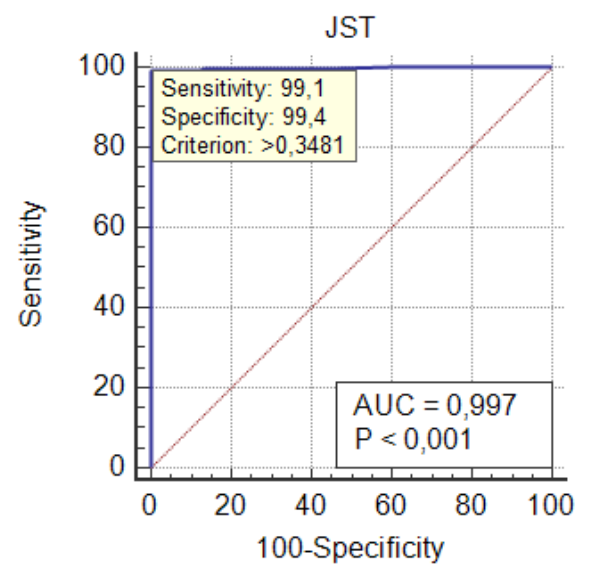

Gambar 4. Kurva ROC Data Training

Pada gambar di atas didapatkan hasil klasifikasi terbaik pada data training yaitu pada saat cut off point berada pada nilai 0,3481. Sehingga didapatkan nilai sensitifitas sebesar 99,1\% dan spesifisitas $99,4 \%$. Di bawah ini merupakan hasil tabulasi silang antara kelas output data training dengan hasil klasifikasi menggunakan metode JST Backpropagation adalah sebagai berikut :

Tabel 8. Hasil JST Data Training

\begin{tabular}{|lcc|}
\hline \multirow{2}{*}{ Kelas } & \multicolumn{2}{c|}{ Hasil JST (\%) } \\
\cline { 2 - 3 } & Tidak Aktif & Aktif \\
\hline Tidak Aktif & 99,43 & 0,57 \\
Aktif & 0,86 & 99,14 \\
\hline
\end{tabular}

Berdasarkan tabel diatas, didapatkan bahwa ketepatan JST Backpropagation dalam klasifikasi data training untuk mahasiswa tidak aktif sebesar 99,43\% dan mahasiswa aktif sebesar 99,14\%, sehingga dapat disimpulkan bahwa metode JST Backpropagation cukup baik digunakan untuk klafisikasi data training pada status mahasiswa Prodi Statistika Universitas Terbuka. 
Nilai bobot dan bias yang didapatkan pada proses data training digunakan untuk validasi data testing dengan menggunakan cut off point sebesar 0,3481 maka didapatkan hasil ketepatan klasifikasi data testing pada tabel 9 berikut ini.

Tabel 9. Hasil JST Data Testing

\begin{tabular}{|lcc|}
\hline \multirow{2}{*}{ Kelas } & \multicolumn{2}{c|}{ Hasil JST (\%) } \\
\cline { 2 - 3 } Tidak Aktif & Tidak Aktif & Aktif \\
\cline { 2 - 3 } Aktif & 94,00 & 6,00 \\
& 6,06 & 93,94 \\
\hline
\end{tabular}

Berdasarkan tabel di atas, didapatkan bahwa ketepatan JST Backpropagation dalam klasifikasi data testing untuk mahasiwa tidak aktif sebesar $94,00 \%$ dan yang aktif tepat sebesar 93,94\%, sehingga dapat disimpulkan bahwa metode JST Backpropagation cukup baik untuk klasifikasi data testing pada status mahasiswa Prodi Statistika UT.

\section{KESIMPULAN}

Parameter dalam pengklasifikasian status mahasiswa Prodi Statistika dengan menggunakan metode Jaringan Syaraf Tiruan Backpropagation berjumlah 15 parameter yang terdiri dari jenis kelamin, usia, pendidikan (SLTA/SMK, Diploma, S1, S2), status pernikahan, status pekerjaan (tidak bekerja, karyawan swasta, wiraswasta, PNS), tahun registrasi awal, jumlah registrasi, SKS tempuh, dan IPK. Akurasi ketepatan klasifikasi dengan Jaringan Syaraf Tiruan Backpropagation adalah sangat baik dengan hasil ketepatan klasifikasi pada data training untuk mahasiswa tidak aktif sebesar 99,43\% dan mahasiswa aktif sebesar 99,14\%. Sedangkan pada data testing untuk mahasiswa tidak aktif sebesar 94,00\% dan yang aktif tepat sebesar 93,94\%. Jadi dari penelitian ini dapat disimpulkan JST Backpropagation merupakan salah satu metode yang sangat baik dalam penerapan metode klasifikasi pada mahasiswa Statistika Universitas Terbuka.

\section{DAFTAR PUSTAKA}

[1] "Prodi Statistika." http://fst.ut.ac.id/index.php/statistika-s1/.

[2] Universitas Terbuka, Catalog UT. 2020.

[3] "UT." https://www.ut.ac.id/tentang-ut.

[4] F. Izhari, M. Zarlis, and Sutarman, "Analysis of backpropagation neural neural network algorithm on student ability based cognitive aspects," IOP Conf. Ser. Mater. Sci. Eng., vol. 725, no. 1, pp. 0-6, 2020, doi: 10.1088/1757-899X/725/1/012103.

[5] N. D. Roman, F. Bre, V. D. Fachinotti, and R. Lamberts, "Application and characterization of metamodels based on artificial neural networks for building performance simulation: A systematic review," Energy Build., vol. 217, p. 109972, 2020, doi: 10.1016/j.enbuild.2020.109972.

[6] S. Haykin, Neural networks: a comprehensive foundation. Prentice-Hall, Inc., 2007.

[7] J. D. Paola and R. A. Schowengerdt, "A review and analysis of backpropagation neural networks for classification of remotely-sensed multi-spectral imagery," Int. J. Remote Sens., vol. 16, no. 16, pp. 3033-3058, 1995, doi: 10.1080/01431169508954607.

[8] H. Chiroma et al., "Progress on Artificial Neural Networks for Big Data Analytics: A Survey," IEEE Access, vol. 7, no. c, pp. 70535-70551, 2019, doi: 10.1109/ACCESS.2018.2880694.

[9] S. Hasanah, "Islamic Countries Society of Statistical Sciences," in Comparison Of Method Classification Artificial Neural Network Back Propagation, Logistic Regression, And Multivariate Adaptive Regression Splines (Mars) (Case Study Data Of Unsecured Loan), 2014, pp. 477-486, [Online]. Available: www.isoss.net.

[10] F. Boithias, M. El Mankibi, and P. Michel, "Genetic algorithms based optimization of artificial neural network architecture for buildings' indoor discomfort and energy consumption prediction," Build. Simul., vol. 5, no. 2, pp. 95-106, 2012, doi: 10.1007/s12273-012-0059-6.

[11] K. Kalyan, B. Jakhia, R. D. Lele, M. Joshi, and A. Chowdhary, "Artificial Neural Network Application in the Diagnosis of Disease Conditions with Liver Ultrasound Images," Adv. Bioinformatics, vol. 2014, 2014, doi: $10.1155 / 2014 / 708279$.

[12] H. Y. Shi et al., "Comparison of artificial neural network and logistic regression models for predicting in-hospital mortality after primary liver cancer surgery," PLoS One, vol. 7, no. 4, 2012, doi: 10.1371/journal.pone.0035781.

[13] R. P. Raymundo and D. M. S. Raymundo, "Artificial Neural Network Model and Multiple Regression Analysis 
Model in Predicting Rainfall - the Case of Isabela, Philippines,” J. Arts Sci., vol. 5, no. 4, pp. $243-263,2012$.

[14] G. Aksu, C. O. Güzeller, and M. T. Eser, "The Effect of the Normalization Method Used in Different Sample Sizes on the Success of Artificial Neural Network Model,” Int. J. Assess. Tools Educ., vol. 6, no. 2, pp. 170-192, 2019, doi: 10.21449/ijate.479404.

[15] M. S. Mirtalaei, M. Saberi, O. K. Hussain, B. Ashjari, and F. K. Hussain, "A trust-based bio-inspired approach for credit lending decisions," Computing, vol. 94, no. 7, pp. 541-577, 2012, doi: 10.1007/s00607-012-0190-3. 
